\title{
Agility matters! Agile Mechanisms in IT Governance and their Impact on Firm Performance
}

\author{
Sulejman Vejseli \\ University of the West of Scotland \\ sulejman.vejseli@hhz.de
}

\author{
Alexander Rossmann \\ Reutlingen University \\ Alexander.Rossmann@Reutlingen- \\ University.de
}

\author{
Thomas Connolly \\ University of the West of Scotland \\ Thomas.Connolly@uws.ac.uk
}

\begin{abstract}
With significant advancements in digital technologies, firms find themselves competing in an increasingly dynamic business environment. It is of paramount importance that organizations undertake proper governance mechanisms with respect to their business and IT strategies. Therefore, IT governance (ITG) has become an important factor for firm performance. In recent years, agility has evolved as a core concept for governance, especially in the area of software development. However, the impact of agility on ITG and firm performance has not been analyzed by the broad scientific community. This paper focuses on the question, how the concept of agility affects the ITG-firm performance relationship. The conceptual model for this question was tested by a quantitative research process with 400 executives responding to a standardized survey. Findings show that the adoption of agile principles, values, and best practices to the context of ITG leads to meaningful results for governance, business/IT alignment, and firm outcome.
\end{abstract}

\section{Introduction}

With significant advancements in digital technologies, firms find themselves competing in an increasingly dynamic business environment. As such, the logic of business decisions is based on the agility and flexibility to sense and respond to emerging trends in an integrated and proactive manner. Therefore, it is of paramount importance that organizations undertake proper governance with respect to their business and IT strategies and the corresponding changes in structures, processes, and services [1]. Within this development, IT governance (ITG) has become an important factor for the success of organizations.

Implementing ITG effectively requires a set of instruments to encourage congruence with a firm's mission, strategies, values, norms, and culture $[2,3]$, which in turn leads to desirable IT behaviors and governance outcomes [3]. A common framework in the literature defines ITG as consisting of structures, processes, and relational mechanisms working together to ensure that business and IT objectives are aligned. In turn, a higher level of business/IT alignment leads to higher firm performance [4].

Traditional ITG relies on hierarchy and standardized mechanisms that provide stable procedures for proper decisions on IT. Such models are limited when it comes to the frequent introduction of innovative technologies and dynamic change [5]. Furthermore, traditional methodologies, reference guides, best practices (e.g. COBIT), and frameworks, such as the IT Infrastructure Library or so-called conventional and traditional models, are considered too structured and, thus, inflexible [6] to ensure proper alignment between business and IT [7].

By contrast, agility has evolved as a core concept for governance in recent years, especially in the area of software development. Independent of the business area, agile principles can add value to business organizations through effective communication and collaboration between different stakeholders [8].

However, to date, the concept of agility has not been analyzed by the broad scientific community in the ITG literature. Therefore, empirical evidence of the role of agility in an effective ITG framework is missing. In particular, a definition of agility and the specific contribution of agility to better business/IT alignment remain vague. To address these gaps in research, this paper focuses on the following core research question (RQ): How does the concept of agility affect the ITG-firm performance relationship?

We executed a well-structured research process to answer this RQ. To do so, we relied on Wu et al.'s [9] study as a theoretical foundation for the ITG-firm performance relationship. The causal model in the current research was enhanced by several qualitative studies on the notion of agility and the operationalization of items for the measurement of 
agility [10-12]. Following this research stream, we integrated agility as a major aspect of governance in the ITG-firm performance relationship. We tested our conceptual model using a quantitative research process with 400 executives responding to a standardized survey. Moreover, we used partial least squares structural equation modeling (PLS-SEM) to assess the quality of the measurement models and the relationships formulated in the path model. The results provide evidence that the adoption of agile principles, values, and best practices to the context of ITG leads to meaningful results for governance, business/IT alignment, and firm performance.

\section{Theoretical Foundation}

\subsection{Traditional ITG and Firm Performance}

Firms needs to employ well-designed, wellunderstood, and transparent ITG mechanisms [2, 3] to reach the ultimate goal of effective alignment between business and IT [4]. That is, implementing an effective ITG in a firm can ensure alignment between business and IT goals and help improve IT performance [2]. Previous studies illustrate that effective ITG leads to higher returns on assets [3] and provides firms with new business opportunities [2, 13]. However, determining the right ITG mechanisms is complex, and managers must recognize that what strategically works for one firm may not necessarily work for another [14]; that is, effective ITG does not happen by accident, and consequently top-performing firms should carefully design their ITG framework. Specifically, firms can assess the effectiveness of their ITG by evaluating how well it enables IT to deliver on four objectives: cost-effectiveness, asset utilization, business growth, and business flexibility [15]. Thus, several studies have argued that an effective ITG requires a framework based on a mixture of three major dimensions: (1) structures, (2) processes, and (3) relational mechanisms $[3,14,16]$ :

ITG structures represent formal structures among defined IT executives, accounts, and committees and councils and consist of formal positions, roles, and responsibilities for IT-related decision making [17] to ensure business/IT alignment. Examples are the institutionalization of boards, committees, councils, and structures that enable CIOs (chief information officers) or COOs (chief operation officers) to report to CEOs (chief executive officers) [14].

ITG processes refer to "the formalization and institutionalization of strategic IT decision-making and IT monitoring procedures, to ensure that daily behaviors are consistent with policies and provide input back to decisions" [18, p. 113]. Conventional processes might contain portfolio management, IT budget control and reporting, metric and compliance processes, project governance methodologies, or information systems planning. In general, ITG processes can help assist firm plans and organize and control strategic IT decisions [3, 17].

ITG relational mechanisms allow firms to discuss and find broader solutions to unleash the creativity of collaborative exploration of solutions that exceed functional boundaries [5]. Examples are a shared understanding of business/IT objectives, crossfunctional business/IT training, and collaboration between principal stakeholders. The objective of such communication mechanisms is to improve IT managers' understanding of business needs so that they can act proactively [19].

In summary, ITG mechanisms directly tap into the alignment concept that firm performance is the consequence of fit between two or more factors such as strategy, structure, technology, culture, and environment and fosters cross-domain interconnectedness between business and IT departments $[4,20]$. Thus, it can be concluded that ITG mechanisms enable shared understanding between the $\mathrm{CIO}$ and the top management team on a strategical level as well as among employees on an operational level [20]. Taken together, we propose the following:

Hla: Traditional ITG mechanisms have a positive impact on business/IT alignment.

\subsection{The Notion of an Ambidextrous ITG}

Current research provides evidence that an effective ITG positively affects business/IT alignment and firm performance. A core issue in this relationship is how the effectiveness of ITG is defined in the digital era. Recently, this issue had led to a call for an ambidextrous ITG. As Romanelli and Tushman [21] showed, successful organizations alternate between two states in their organizational development. The first state is characterized by a phase of environmental stability, in which firms strive for optimization within their existing business logic by focusing on minor, incremental adjustments in operational efficiency and benefit from economies of scale [22]. The second state is characterized by fast-changing and highly volatile environmental conditions, in which major organizational adjustments are required to successfully manage the change [23]. This view of organizational development is referred to as punctuated equilibrium theory. Depending on which state the organization is in, it should design adequate governance mechanisms to deal successfully with the specific challenges of each state [24]. Thus, the 
distinction of these two states is important for the design of governance structures and mechanisms.

One way for firms to deal with these two states is to become ambidextrous [22]; here, firms have the ability "to both explore and exploit - to compete in mature technologies and markets where efficiency, control, and incremental improvement are prized and to also compete in new technologies and markets where flexibility, autonomy, and experimentation are needed" [25, p. 324]. During the exploitation state, the organization focuses on activities to improve efficiency and reduce variance, while in the exploration state, it concentrates on discovery and innovation activities [26]. In context of governing IT, this implies that an ambidextrous ITG is needed which should enable promoting IT function's ability to simultaneously explore new IT opportunities and innovations (IT exploration) as well as exploit existing IT resources and practices (IT exploitation) [27]. Thus, traditional hierarchical governance structures should be complemented by network-like governance structures that can react quickly to changes in the organization's environment.

In a recent study, Vejseli et al. [10] investigated this topic by conducting a qualitative analysis with 33 firms. As a main finding, they uncovered 22 traditional and 27 agile ITG mechanisms, grouped under the traditional magnitudes of structures, processes, and relational mechanisms that firms use to govern IT in digital transformations projects. In conclusion, the governance of IT can address both traditional and agile mechanisms without significant disruption. This sets a formal model for a punctuated equilibrium theory by referring to traditional ITG mechanisms complemented by agile strategies.

\subsection{The Agile Aspect within ITG}

Agility is important to adapt to a changing environment. Consequently, in recent years the term "agile" has gained increased attention from practitioners and academics because of its importance for the competitive performance of firms in contemporary business environments [28]. Especially, IT agility is considered to be a main driver of the IT function's ability to support digitization [29]. Conceived as an antecedent to organization agility, it encapsulates the ability of the IT function to sense opportunities to innovate and to respond rapidly to competitive actions from a larger repertoire of responses [27]. As such, new ITG and alignment mechanisms need to be developed and established to align a firm's strategic and operational activities with the digital and the traditional IT in a faster and more agile manner [30]. In general, agility refers to "the ability to respond operationally and strategically to changes in the external environment. The response has to be quick and effective for the organization to be considered agile" [31, p. 444]. This definition can serve as a proxy representing the established definitions of agility in current research, allowing us to break them down into single agile ITG mechanisms. However, limited research has combined agile strategies with governance frameworks $[6,32]$.

The most compelling research with respect to an agile ITG is that of Luna et al. [6]. In their study, the researchers present a new concept of agile ITG in which principles, values, and practices of the agile paradigm from software engineering are translated into the context of ITG. They suggest enhancing the ITG mechanisms by the values and principles of the agile manifesto of software engineering introduced by Beck et al. [33]. With regard to the concept of Luna et al. [6], implementing agile strategies with such agile practices can complement the agile principles within traditional ITG. Thus, agile mechanisms derived from implementing agile strategies in the context of ITG could encompass variants of activities that determine lean team structures, short decision-making processes, fast information flows, and communication efforts related to projects. In summary, we understand agile ITG mechanisms as practices where speed [34] and flexibility [35] are key elements to promote IT agility.

Vejseli et al.'s [11] recent study explored this topic by providing an extended list of agile ITG mechanisms. That research systematically explored effective agile ITG mechanisms according to a defined process in which a combination of steps from scale development procedures and phases of a Delphi analysis were used. The researchers conducted 56 qualitative interviews to uncover a final list of agile ITG mechanisms. Furthermore, all agile elements were rated by 29 experts, which led to the identification of the most effective ones. As a result, 46 agile dimensions were identified, 22 of which were rated as effective. Thus, as the aim of ITG is to achieve strategic business/IT alignment, such agile strategies within the ITG framework might help improve communication and collaboration and lead to both better alignment between business and IT and enhanced responsiveness to business transformation. Thus, we state our second hypothesis as follows:

H1b: Agile ITG mechanisms have a positive impact on business/IT alignment.

\subsection{Business/IT Alignment as a Mediator}

Business/IT alignment is the most investigated dimension in the ITG-firm performance relationship and is considered one of the important mediating 
factors necessary in the chain of value creation [36]. In a recent literature analysis, Vejseli and Rossmann [12] explored 34 highly relevant articles on the relationship between ITG and firm performance to identify key impact variables. One main finding was that business/IT alignment takes on a major role in the governance-performance link. Given this analysis, business/IT alignment can further be conceptualized as a key impact variable acting as a mediator in the ITG-performance link.

In general, the literature divides business/IT alignment into two dimensions: (1) the intellectual and (2) the social [37]. Intellectual business/IT alignment refers to "the state in which a high-quality set of interrelated IT and business plans exist" [38, p. 82]. By contrast, the social business/IT alignment reflects "the state in which business and IT executives understand each other and are committed to the business and IT mission, objectives and plans" [38, p. 82] and relates to the human behavior that is socially organized among different actors [39].

Therefore, intellectual business/IT alignment represents a knowledge integration outcome and, as such, reflects an alignment state resulting from the social linkage between human actors in business and IT ensured through ITG mechanisms, which in turn leads to a better business outcome [37]. In summary,

However, the agile aspect within ITG frameworks becomes a crucial factor to better aligning business and IT [6]. In their studies, Vejseli et al. [10, 11] found that specific management actions in terms of agile mechanisms include establishing cross-boundary committees to integrate all stakeholders, designing a steering system to break down actions from the program level to the project and team levels, initiating and fostering communication, benchmarking between programs and projects, and sharing information and success. As determinants of business/IT alignment are likely to be ITG mechanisms that drive alignment [9], we argue, that such agile mechanisms may promote social alignment, which, in turn can facilitate emergent coordination between business and IT when sudden changes occur [40]. As such, agile mechanisms may enhance the social behavior framework of the traditional ITG mechanisms that promote shared understanding between shareholders and stakeholder, which can lead to better business/IT alignment and, thus, a higher business outcome [11]. Therefore, both the traditional and the agile ITG mechanisms provide the contextual framework for business and IT people to be involved in IT decision making. Consequently, we state our third hypothesis as follows:

H2: Intellectual business/IT alignment mediates the positive impact of traditional ITG mechanisms and agile ITG mechanisms on firm performance.

\section{Research Model}

The resource-based view can help better illustrate the relationship between an effective ITG framework containing agile and traditional ITG mechanisms and its impact on firm performance through the mediating factor of (intellectual) business/IT alignment. ITG mechanisms are understood as human IT resources reflecting "combinations of investment allocations and a mutually reinforcing system of competencies and practices" [41, p. 765] that complement IT in delivering value to firms. According to the resourcebased view, firm resources are the main predictors of firm performance [42, 43], and IT resources can differentiate in corporate strategies [9, 44]. Thus, in terms of ITG mechanisms, firms should foster a mixture of inimitable traditional and agile structures, processes, and relational mechanisms and leverage core resources to combine business and IT knowledge and support business objectives [10]. Consequently, IT strategic alignment will result as outcomes that are the product of the alignment process through ITG mechanisms, that is, the strategies contained in the business plan and the IT plan. This, in turn, may result in better firm performance through IT-based value creation [36, p. 27]. Wu et al. [9] adopted this concept and showed that the intellectual dimension of business/IT alignment fully mediates the impact of ITG mechanisms on firm performance. The current study uses their research model as an initial point in the literature to further investigate the link among ITG, business/IT alignment, and firm performance. However, the model in this study extends this conceptual framework through agile mechanisms within the governance construct (Figure 1).

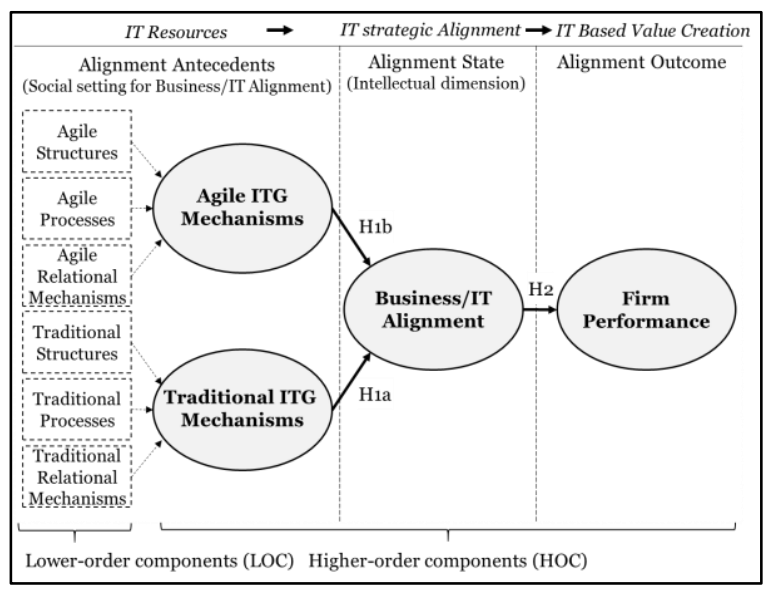

Figure 1: Research model (adapted from [9]) 


\section{Research Methodology}

\subsection{Data Collection and Sample}

We collected survey data from a sample of experts for governance and digital transformation projects working in firms with 50 or more full-time employees and having personal responsibility in their current job position, by using a representative panel book of an international online consumer panel company with panelists across Germany. However, before administering the survey to potential respondents, we pre-tested the questionnaire with scholars and 183 employees of a financial institution to identify potential issues with the wording, question order, and the navigation of the survey instrument [45]. Then, the survey was sent to 678 experts who first needed to indicate if they have executive responsibility in their current position. If they indicated no, they were screened out from the analysis. We also requested the respondents to provide some demographic information on themselves and on their firm (Table 1). Moreover, the survey included a dummy question to identify unserious respondents. Finally, a sample size of 400 completed surveys (response rate 59\%) resulted.

Table 1. Sample demographics $(n=400)$

\begin{tabular}{|l|c|c|}
\hline Industry & $\boldsymbol{n}$ & $\mathbf{\%}$ \\
Automotive & 22 & 5.50 \\
Banking, Insurance & 41 & 10.25 \\
Construction & 14 & 3.25 \\
Consulting, Services & 21 & 5.25 \\
Energy, Electrical & 17 & 4.25 \\
Food Trade & 31 & 7.75 \\
IT & 46 & 11.50 \\
Healthcare, Chemistry & 46 & 11.50 \\
Non-profit & 28 & 7.00 \\
Telecom, Media & 13 & 3.25 \\
Transportation & 36 & 9.00 \\
Public, Education & 11 & 2.75 \\
Mechanical, Metal & 13 & 3.25 \\
Other & 61 & 15.25 \\
\hline Firm Size (Number of employees) & $\boldsymbol{n}$ & $\mathbf{\%}$ \\
$51-250$ & 10 & 2.50 \\
251-1,000 & 153 & 38.25 \\
1,001 - 5,000 & 121 & 30.25 \\
$5,001-10,000$ & 42 & 10.50 \\
$>10,000$ & 74 & 18.50 \\
\hline Country & $\boldsymbol{n}$ & $\mathbf{\%}$ \\
Germany & 381 & 95.25 \\
Austria & 13 & 3.25 \\
Swiss & 4 & 1.00 \\
Other & 2 & .50 \\
\hline
\end{tabular}

\begin{tabular}{|l|c|c|}
\hline Position & $\boldsymbol{n}$ & $\boldsymbol{\%}$ \\
Executive & 55 & 13.75 \\
Middle management & 178 & 44.50 \\
Team Lead & 145 & 36.25 \\
Specialist & 22 & 5.50 \\
\hline
\end{tabular}

\subsection{Measurement and Validation Steps}

As our research model partly builds on existing constructs, such as the traditional ITG mechanisms, business/IT alignment, and firm performance, we relied on scales established in prior literature. However, indicators for agile ITG dimensions were applied from Vejseli et al. [11]. Similar to the study of Wu et al. [9], we designed all indicators formatively. Therefore, our conceptualized ITG framework is represented by a set of traditional and agile structures, processes, and relational mechanisms that do not necessarily need to be correlated or similar in their dimensions (e.g. steering committees, portfolio management, leadership). Similarly, the individual applied indicators of business/IT alignment and firm performance, as proposed by $\mathrm{Wu}$ et al. [9], do not necessarily covary in their dimensions and also are not interchangeable. Therefore, formative measures are applicable for the applied constructs. For all measurement items, we adopted 7-point Likert scales. However, we included higher-component models (HCM) in our research model to reduce the relationships and, in doing so, make the path model parsimonious and easier to apprehend [46]. In detail, we grouped indicators into lower-order components (LOCs), which in turn explain the higher-order component (HOC). In terms of the governance framework, the LOCs represent both the agile and the traditional structures, processes, and relational mechanisms, measured through individual indicators and then mapped onto the HOC of "agile ITG mechanisms" or "traditional ITG mechanisms," respectively. We applied the same idea to the HOCs "business/IT alignment" and "firm performance." Table 2 provides an overview of the relationships between the LOCs and the HOCs, the literature references for the construct operationalizations, and the item abbreviations used in this study. Due to page limitations, further details on the formulation of the individual measurement scales are not available in this version of the paper.

We validated the measurement instruments via PLS-SEM using SmartPLS 3 [47]. The motivation for applying PLS-SEM approach for data evaluation is due mainly to two reasons. First, all our measurement models are of a formative nature, and PLS-SEM is well suited to handle formatively measured constructs 
[48]. Second, this research requires a large number of indicators for the constructs to be validated. For this reason, HCMs are integrated into the measurement models. Furthermore, mediation effects need to be analyzed in the structural model. Thus, our model takes a complex form because it comprises many relationships. Hair et al. [46] advise using the PLSSEM approach when estimating models with complex latent variables or when formative items are included in the measurement model.

Table 2. Construct operationalization

\begin{tabular}{|c|c|c|c|}
\hline $\mathrm{HOC}$ & LOC Construct & Item abbreviations & Source \\
\hline \multirow{3}{*}{ 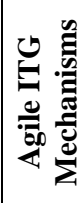 } & Agile structures & ITG_AS1 - ITG_AS5 & \multirow{3}{*}{ [11] } \\
\hline & Agile processes & ITG_AP1 - ITG_AP5 & \\
\hline & $\begin{array}{l}\text { Agile relational } \\
\text { mechanisms }\end{array}$ & ITG_AM1 - ITG_AM7 & \\
\hline \multirow{3}{*}{ 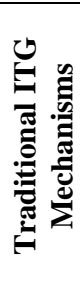 } & \begin{tabular}{|l}
$\begin{array}{l}\text { Traditional } \\
\text { structures }\end{array}$ \\
\end{tabular} & ITG_TS1 - ITG_TS5 & \multirow{3}{*}{$\begin{array}{c}{[4] ;[3] ;} \\
{[9]}\end{array}$} \\
\hline & $\begin{array}{l}\text { Traditional } \\
\text { processes }\end{array}$ & ITG_TP1 - ITG_TP5 & \\
\hline & $\begin{array}{l}\text { Traditional } \\
\text { relational } \\
\text { mechanisms }\end{array}$ & ITG_TM1 - ITG_TM5 & \\
\hline \multirow{3}{*}{ 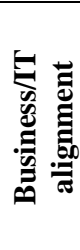 } & \begin{tabular}{|l}
$\begin{array}{l}\text { Product strategic } \\
\text { alignment }\end{array}$ \\
\end{tabular} & ALIN_P1 - ALIN_P6 & \multirow{3}{*}{ [9] } \\
\hline & $\begin{array}{l}\text { Quality strategic } \\
\text { alignment } \\
\end{array}$ & ALIN_Q1 - ALIN_Q6 & \\
\hline & $\begin{array}{l}\text { Market strategic } \\
\text { alignment }\end{array}$ & ALIN_M1 - ALIN_M4 & \\
\hline \multirow{3}{*}{ 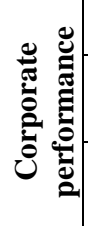 } & Financial results & PERF_F1 - PERF_F3 & \multirow{3}{*}{ [9] } \\
\hline & $\begin{array}{l}\text { Operational } \\
\text { excellence }\end{array}$ & PERF_O1 - PERF_O3 & \\
\hline & $\begin{array}{l}\text { Customer } \\
\text { perspective }\end{array}$ & PERF_C1 - PERF_C3 & \\
\hline
\end{tabular}

To validate our research model, we mainly followed four evaluation steps, which are based on Hair et al. [46]. These include evaluation of the (1) measurement models, (2) HCMs, (3) structural model, and (4) mediating effects.

Step 1: Evaluation of the measurement models: In this step, we relied on evaluation criteria that examine the fit of the formative measurement models. As our research model contains only formative measures, it mainly must prove collinearity among indicators, significance, and relevance of weights. Furthermore, in case of non-significance of the weights, the significance of the loadings needs to be assessed.

Step 2: Evaluation of the HCMs: The relationships between the indicators and the LOCs as well as the ones of the LOCs to the corresponding HOC are of a formative nature. Therefore, a formative-formative HCM emerged (type IV). Following the guidelines of Hair et al. [49], we used both approaches for the specification of the HCMs: the repeated indicators approach for the exogenous variables and the twostage approach for the endogenous constructs. In this way, the evaluation of the HOC measurement model accounts for the path coefficients between the HOC and its LOCs that need to be interpreted as weights in the formative-formative relationships. As such, the same evaluations criteria need to be applied, as in the case of formative measurement models (collinearity and significance of relationships within the HCMs).

Step 3: Evaluation of the structural model: After assessing the measurement model, we evaluated the structural model on the basis of three criteria: (1) collinearity of the constructs, (2) significance and relevance of the path coefficients, and (3) the coefficient of determination $\left(\mathrm{R}^{2}\right)$.

Step 4: Evaluation of the mediating effects: Mediation analysis is carried out to examine the causal relationship between an exogenous variable and endogenous construct through the inclusion of a third explanatory mediator variable [46] (in our case, business/IT alignment). To perform the mediation analysis in PLS-SEM, we first assessed the significance of the direct effect of the exogenous variables on the endogenous variable and then analyzed the significance of the indirect paths.

\section{Results}

To estimate the path coefficients, indicator weights and loadings, and collinearity statistics, we run the PLS-SEM algorithm by selecting a path-weighting scheme and 5000 maximum iterations. We set the stop criterion to $10^{-7}$. For the calculation of the significance, we applied bootstrapping technique with 5000 iterations. Figure 2 and Table 3 depict the results of the PLS-SEM analysis. 


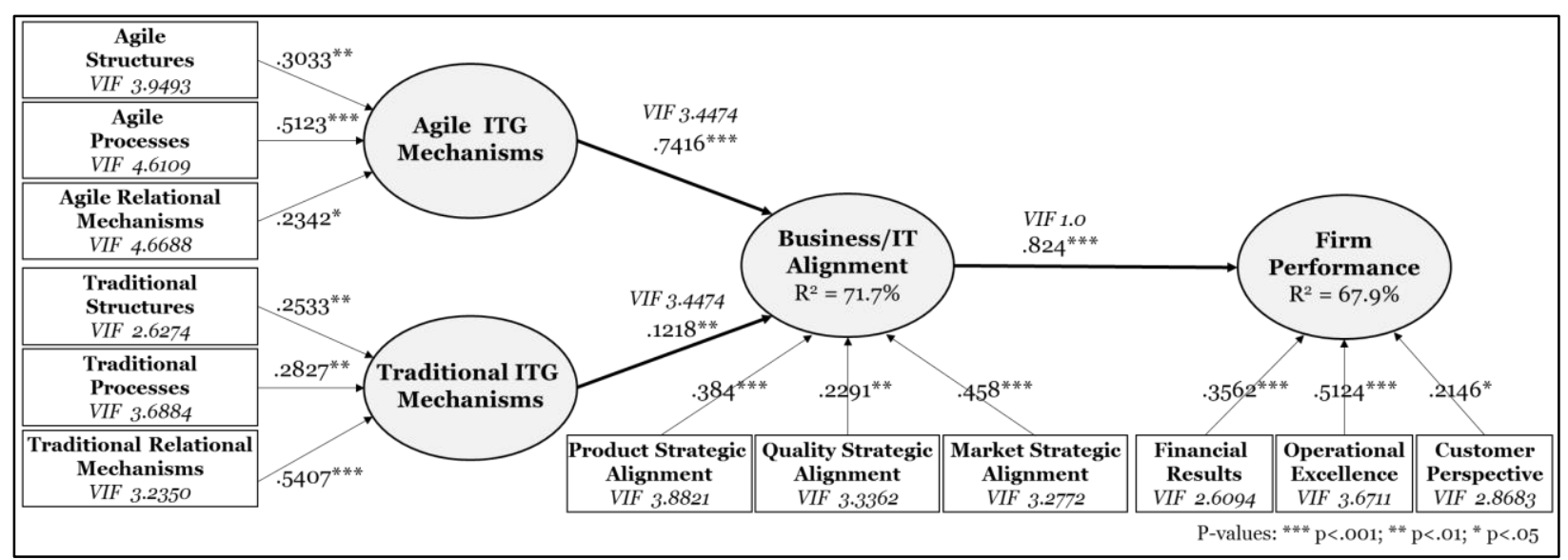

Figure 2. Results of the HCMs and structural model evaluation

\subsection{Evaluation of the Measurement Models}

We first evaluated the measurement models by analyzing the collinearity statistics of the items. To do so, Hair et al. [46] recommend the variance inflation factor (VIF) as a measure of collinearity to determine the degree to which other formative indicators related to the same construct affect any formative indicator. We computed the VIF for every indicator per formative measurement model. A VIF value of 5 and higher indicates a potential collinearity problem. Finally, all VIFs of the indicators had a value below the threshold of 5, thus discounting collinearity issues among the indicators. Then, we examined the significance of the indicator's weights. Of the 57 items, 50 contribute relatively well to their constructs and indicate significant weights at the 5\% level. The majority of the item weights (46 of 57) are even significant at the $1 \%$ level. However, for the nonsignificant item weights, the loadings and their significance must be considered. When a nonsignificant weight provides an outer loading above .50 , it should be interpreted as "absolutely important but not as relatively important" [46, p. 148] and would generally be retained. This is the case for the seven non-significant indicators, all of which provide outer loadings above .50 and are significant at the $1 \%$ level. In conclusion, all indicators can be retained in the model as they contribute sufficiently well to their constructs and do not show any collinearity issues.

\subsection{Evaluation HCMs and Structural Model}

We continued with the assessment of the HCMs and the structural model. Regarding the HCMs we calculated the VIF of each LOC per formative HCM to determine potential collinearity problems. We also examined the significance of the weights to check their contribution. All VIFs between the LOCs per HCM are below the threshold of 5, indicating that collinearity is not an issue among the LOCs. Furthermore, all LOCs contribute well to their corresponding HOC and their weights are significant, at least at the 5\% level. Consequently, all HCMs can be retained in the model.

After analyzing the HCMs we assessed the structural model to test the relationship between the endogenous and exogenous variables. First, we computed the VIF values to check for collinearity issues in the structural model. We concluded that no critical values of collinearity issues are present, as the VIFs indicate values lower than 5. Second, we examined the paths and the coefficient of determination $\mathrm{R}^{2}$. As Figure 2 shows, all paths are significant at least at the 5\% level. While the path coefficient from agile ITG mechanisms to business/IT alignment is .7416 , the path from traditional ITG mechanisms to the same construct is .1218. The path coefficient from business/IT alignment to firm performance is .824. In terms of $\mathrm{R}^{2}$, the model explains $67.9 \%$ of the variance in firm performance and $71.7 \%$ of the variance in business/IT alignment, clearly indicating that the effects analyzed are substantive. Given the results of the analysis, both $\mathrm{H} 1 \mathrm{a}$ and $\mathrm{H} 1 \mathrm{~b}$ are supported.

\subsection{Evaluation of the Mediating Effects}

To carry out a mediation analysis in PLS-SEM, the first step is to check whether the indirect effect of the exogenous construct via the mediator variable is significant [46]. In our research model, this refers to the agile and traditional ITG mechanisms via business/IT alignment. In case of a significant indirect 
effect, a mediation relationship is likely present in the conceptualized model. Then, in the second step, the direct effect needs to be analyzed, which represents the direct connection of the agile and traditional ITG mechanisms with the firm performance construct. If this direct effect is non-significant, an indirect-only mediation (also called "full mediation") occurs, which means that the mediator fully mediates the relationship of an exogenous and endogenous variable [46]. Table 3 clearly shows that business/IT alignment fully mediates the relationship between agile ITG mechanisms and traditional mechanisms on firm performance, as in both paths, the indirect effects are significant at the 5\% level while the direct effects are not. Thus, H2 is supported as well.

Table 3. Direct and indirect effects

\begin{tabular}{|c|c|c|c|c|c|}
\hline 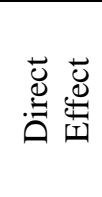 & 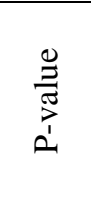 & 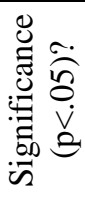 & 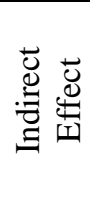 & 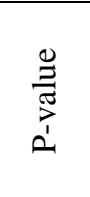 & 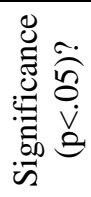 \\
\hline \multicolumn{6}{|c|}{$\begin{array}{c}\text { Path 1: } \\
\text { Agile ITG mechanisms } \rightarrow \text { firm performance }\end{array}$} \\
\hline .0564 & .4690 & No & .5234 & .0000 & Yes \\
\hline \multicolumn{6}{|c|}{$\begin{array}{c}\text { Path 2: } \\
\text { Traditional ITG mechanisms } \rightarrow \text { firm performance }\end{array}$} \\
\hline .0986 & .1098 & No & .0843 & .0153 & Yes \\
\hline
\end{tabular}

\section{Discussion}

This research leads to several theoretical implications for ITG. First, the research results provide support for the integration of the concept of agility in existing ITG frameworks. To date, the definition of agility is quite fuzzy and is unspecified in an ITG context [6]. Therefore, this research contributes to theory by providing a clear definition and operationalization of agility in this specific context (for a further description of the item development procedure, see Vejseli et al. [11]). The relevant items for agility might be organized in a similar mode such as traditional items around structures, processes, and relational mechanisms.

Second, this research also demonstrates that agile ITG mechanisms can be measured independent of traditional ITG mechanisms within one causal model. This is an important theoretical outcome, as such a separation in measurement models allows assessing the current state of ITG in two distinct dimensions. Such a conceptualization offers various pathways for further research initiatives on the different antecedents and effects of traditional and agile ITG mechanisms.

In this research, we focused on the differential effects on business/IT alignment and firm performance. As a theoretical contribution, the results of this study confirm the hypotheses of previous research initiatives on the causal relationship among ITG, business/IT alignment, and firm performance [9]. The results of the PLS analysis explain a large part of the variance of the two endogenous constructs, with $\mathrm{R}^{2}$ of .717 (business/IT alignment) and .679 (firm performance). Moreover, all causal paths in the model are strong and highly significant. Perhaps the most compelling result of this analysis is the relatively high effect of agile ITG mechanisms on business/IT alignment. We show that the integration of agile ITG mechanisms contributes significantly to the explanation of business/IT alignment. Moreover, the direct effect is much higher $(\beta=.7416)$ than traditional ITG mechanisms $(\beta=.1218)$. Consequently, agility plays an important but so-far-neglected role in the relationship among ITG, business/IT alignment, and firm performance.

The managerial implications of this research might refer to an implementation of the observed strategies for effective ITG. To be effective in ITG, firms still need to consider traditional governance mechanisms such as steering committees, the role of the CIO, clear budget control and reporting, and internal communication procedures [4]. Even more important in the digital age is the parallel implementation of agile strategies on the level of governance structures, processes, and relational mechanisms. This leads to a call for an ambidextrous organization and a second mode of ITG with operational issues on multiple levels. Practically, firms need to implement additional governance strategies that focus on interdisciplinarity, co-creation, cooperation with start-ups, rapid prototyping, or transformational leadership. The results of this study imply that firms might be even more successful if they include both traditional and agile mechanisms in their ITG framework [10].

Our study is not without limitations however. First, we used cross-sectional data to evaluate the impact of agile and traditional ITG mechanisms on firm performance mediated through business/IT alignment. It would also be useful to conduct longitudinal research on key antecedents of effective ITG and its consequences. Second, our data are limited to the responses from executives. Future research could employ matched-pair surveying methods based on business and IT responses located at the operational level to improve the objectivity of our results. Finally, our data may be culturally biased, as our sample only includes firms from Germany. 


\section{Conclusion}

Firms need to develop an effective ITG framework if they want to be successful in the digital world. The results of this study provide evidence for a strong causal relationship among ITG, business/IT alignment, and firm performance. Therefore, ITG remains a major discipline for firms in the digital transformation. The traditional conflict between stability in the context of governance and agility in terms of dynamic adaptation calls for an ambidextrous organization and might be resolved through the integration of agile strategies in ITG mechanisms. In such a conceptualization, both traditional and agile mechanisms positively affect business/IT alignment and firm performance. However, agility exerts an even stronger effect on business/IT alignment than traditional ITG mechanisms. Therefore, firms need to develop a basic governance model powered by traditional ITG mechanisms and mutually increase agility in their structures, processes, and relational mechanisms.

\section{References}

[1] P. Barrett, "Evaluation and Performance auditing: Sharing the common ground," in Australasian Evaluation Society-International Conference, 2001, pp. 1-34.

[2] S. Ali and P. Green, "Effective information technology (IT) governance mechanisms: An IT outsourcing perspective," Information Systems Frontiers, vol. 14, no. 2, pp. 179-193, 2012.

[3] P. Weill and J. W. Ross, IT governance: How top performers manage IT decision rights for superior results. Boston, Mass.: Harvard Business School Press, 2004.

[4] S. de Haes and W. van Grembergen, "An Exploratory Study into IT Governance Implementations and its Impact on Business/IT Alignment," Information Systems Management, vol. 26, no. 2, pp. 123-137, 2009.

[5] R. R. Peterson, "Integration Strategies and Tactics for Information Technology Governance," in Strategies for Information Technology Governance, W. van Grembergen, Ed.: Igi Global, 2004, pp. 3780.

[6] A. J. H. Luna, C. P. Costa, H. P. d. Moura, M. A. Novaes, and C. A. do Nascimento, "Agile governance in Information and Communication Technologies: Shifting paradigms," Journal of Information Systems and Technology Management, vol. 7, no. 2, pp. 311-334, 2010.

[7] S. Ramlaoui, A. Semma, and W. Dachry, "Achieving a balance between IT Governance and Agility," International Journal of Computer Science Issues (IJCSI), vol. 12, no. 1, p. 89, 2015.
[8] A. Fruhling, P. McDonald, and C. Dunbar, "A Case Study: Introducing eXtreme Programming in a US Government System Development Project," in Proceedings of the 41st Annual Hawaii International Conference on System Sciences (HICCS 2008), 2008, p. 464.

[9] S. P.-J. Wu, D. W. Straub, and T.-P. Liang, "How Information Technology Governance Mechanisms and Strategic Alignment Influence Organizational Performance: Insights from a Matched Survey of Business and It Managers," MIS Quarterly, vol. 39, no. 2, pp. 497-518, 2015.

[10] S. Vejseli, D. Proba, A. Rossmann, and R. Jung, "The agile strategies in IT Governance: Towards a framework of agile IT Governance in the banking industry," in Proceedings of the 25th European Conference on Information Systems (ECIS 2018), 2018.

[11] S. Vejseli, A. Rossmann, and T. Connolly, "IT Governance and Its Agile Dimensions: Exploratory Research in the Banking Sector," in Proceedings of the 52nd Hawaii International Conference on System Sciences (HICCS 2019), 2019.

[12] S. Vejseli and A. Rossmann, "The Impact of IT Governance on Firm Performance A Literature Review," in Proceedings of the 21st Pacific Asia Conference on Information Systems (PACIS 2017), 2017.

[13] J. Sampler and P. Weill, "Core incompetencies," Research Briefing, III, no. 1B, 2003.

[14] S. de Haes and W. van Grembergen, "IT governance and its mechanisms," Information Systems Control Journal, vol. 1, pp. 27-33, 2004.

[15] P. Weill and J. Ross, "A matrixed approach to designing IT governance," MIT Sloan management review, vol. 46, no. 2, p. 26, 2005.

[16] IT Governance Institute, Board Briefing on IT Governance. Rolling Meadows, IL, USA, 2003.

[17] G. L. Lunardi, A. C. G. Maçada, J. L. Becker, and W. van Grembergen, "Antecedents of IT Governance Effectiveness: An Empirical Examination in Brazilian Firms," Journal of Information Systems, vol. 31, no. 1, pp. 41-57, 2017.

[18] S. de Haes and W. van Grembergen, Enterprise Governance of Information Technology: Achieving Alignment and Value, Featuring COBIT 5: Springer International Publishing, 2015.

[19] C. Burtscher, S. Manwani, and D. Remenyi, "Towards a Conceptual Map of IT Governance: a review of current academic and practitioner thinking," in Proceedings of the UK Academy for Information Systems Conference (UKAIS 2009), 2009, p. 15.

[20] F. Schlosser, D. Beimborn, T. Weitzel, and H.-T. Wagner, "Achieving social alignment between business and IT - an empirical evaluation of the efficacy of IT governance mechanisms," Journal of Information Technology, vol. 30, no. 2, pp. 119-135, 2015.

[21] E. Romanelli and M. L. Tushman, "Organizational transformation as punctuated equilibrium: An 
empirical test," Academy of Management Journal, vol. 37, no. 5, pp. 1141-1166, 1994.

[22] M. L. Tushman and C. A. O'Reilly, "Ambidextrous Organizations: Managing Evolutionary and Revolutionary Change," California Management Review, vol. 38, no. 4, pp. 8-29, 1996.

[23] M. L. Tushman, W. H. Newman, and E. Romanelli, "Convergence and Upheaval: Managing the Unsteady Pace of Organizational Evolution," California Management Review, vol. 29, no. 1, pp. 29-44, 1986.

[24] D. C. Dunphy and D. A. Stace, "Transformational and Coercive Strategies for Planned Organizational Change: Beyond the O.D. Model," Organization Studies, vol. 9, no. 3, pp. 317-334, 1988.

[25] C. A. O'Reilly and M. L. Tushman, "Organizational Ambidexterity: Past, Present, and Future," Academy of Management Perspectives, vol. 27, no. 4, pp. 324338,2013

[26] C. C. Markides, "Business Model Innovation: What Can the Ambidexterity Literature Teach US?," Academy of Management Perspectives, vol. 27, no. 4, pp. 313-323, 2013.

[27] I. Haffke, B. Kalgovas, and A. Benlian, "The Transformative Role of Bimodal IT in an Era of Digital Business," in Proceedings of the 50th Hawaii International Conference on System Sciences (HICSS 2017): Association for Information Systems, 2017, pp. 1-10.

[28] V. Sambamurthy, A. Bharadwaj, and V. Grover, "Shaping agility through digital options:

Reconceptualizing the role of information technology in contemporary firms," MIS Quarterly, pp. 237263, 2003.

[29] D. Leonhardt, I. Haffke, J. J. Kranz, and A. Benlian, "Reinventing the IT function: The Role of IT Agility and IT Ambidexterity in Supporting Digital Business Transformation," in Proceedings of the 25th European Conference on Information Systems (ECIS 2017): Association for Information Systems, 2017, pp. 968-984.

[30] B. Horlach, P. Drews, and I. Schirmer, "Bimodal IT: Business-IT alignment in the age of digital transformation," Multikonferenz. Wirtschaftsinformatik (MKWI), pp. 1417-1428, 2016.

[31] L. Fink and S. Neumann, "Gaining agility through IT personnel capabilities: The mediating role of IT infrastructure capabilities," Journal of the Association for Information Systems, vol. 8, no. 8, pp. 440-462, 2007.

[32] A. J. H. Luna, P. Kruchten, and H. P. d. Moura, "GAME: Governance for Agile Management of Enterprises: A Management Model for Agile Governance," in Proceedings of the 8th International Conference on Global Software Engineering (ICGSE 2013), 2013, pp. 88-90.

[33] K. Beck et al., The agile manifesto. Available: http://agilemanifesto.org (visited on 04/25/2019).
[34] K. Lyytinen and G. M. Rose, "Information system development agility as organizational learning," European Journal of Information Systems, vol. 15, no. 2, pp. 183-199, 2006.

[35] J. Highsmith, Agile project management: creating innovative products: Pearson education, 2009.

[36] R. Kohli and V. Grover, "Business Value of IT: An Essay on Expanding Research Directions to Keep up with the Times," Journal of the Association for Information Systems, vol. 9, no. 1, pp. 23-39, 2008.

[37] F. Schlosser, "Mastering the Social IT/Business Alignment Challenge," in Proceedings of the 18th Americas Conference on Information Systems (AMCIS 2012), 2012.

[38] B. H. Reich and I. Benbasat, "Factors That Influence the Social Dimension of Alignment between Business and Information Technology Objectives," MIS Quarterly, vol. 24, no. 1, pp. 81-113, 2000.

[39] C. Alaceva and L. Rusu, "Barriers in achieving business/IT alignment in a large Swedish company: What we have learned?," Computers in Human Behavior, vol. 51, pp. 715-728, 2015.

[40] H. Liang, N. Wang, Y. Xue, and S. Ge, "Unraveling the Alignment Paradox: How Does Business - IT Alignment Shape Organizational Agility?," Information Systems Research, vol. 28, no. 4, pp. 863-879, 2017.

[41] S. Aral and P. Weill, "IT Assets, Organizational Capabilities, and Firm Performance: How Resource Allocations and Organizational Differences Explain Performance Variation," Organization Science, vol. 18, no. 5, pp. 763-780, 2007.

[42] J. Barney, "Firm Resources and Sustained Competitive Advantage," Journal of Management, vol. 17, no. 1, pp. 99-120, 1991.

[43] R. Hall, "The strategic analysis of intangible resources," Strategic Management Journal, vol. 13, no. 2, pp. 135-144, 1992.

[44] A. S. Bharadwaj, "A Resource-Based Perspective on Information Technology Capability and Firm Performance: An Empirical Investigation," MIS Quarterly, vol. 24, no. 1, pp. 169-196, 2000.

[45] J. W. Creswell, Educational research: Planning, conducting, and evaluating quantitative and qualitative research. Delhi, India: PHI Learning Private Limited, 2012.

[46] J. F. Hair, G. T. M. Hult, C. M. Ringle, and M. Sarstedt, A primer on partial least squares structural equation modeling (PLS-SEM), 2nd ed. Los Angeles: SAGE, 2016.

[47] C. M. Ringle, S. Wende, and J.-M. Becker, SmartPLS 3: SmartPLS GmbH.

[48] W. W. Chin, "Issues and opinion on structural equation modeling," MIS Quarterly, vol. 22, no. 1, 1998.

[49] J. F. Hair, M. Sarstedt, C. M. Ringle, and S. Gudergan, Advanced issues in partial least squares structural equation modeling. Los Angeles: SAGE, 2017. 